\title{
Single-Station Earthquake Characterization for Early Warning
}

\author{
by Andrew B. Lockman and Richard M. Allen*
}

\begin{abstract}
We use data from 50 earthquakes in southern California to test the accuracy of event parameter determination using single seismic stations for the purpose of early warning. Earthquake magnitude, hypocentral distance, and backazimuth are all estimated using $P$-wave arrivals only. There is a wide range in the accuracy of event parameters determined by different seismic stations. One quarter of the stations produced magnitude estimates with errors less than \pm 0.3 magnitude units, hypocentral distances within $\pm 15 \mathrm{~km}$, and backazimuth calculations within $\pm 20^{\circ}$. This accuracy is sufficient to provide useful early warning. Using $P$-wave arrivals is the most rapid method of delivering earthquake early warning and may permit a few seconds notice of impending ground motion even in the epicentral region. Our results show that networks using a $P$-wave detection approach for early warning can increase the accuracy of magnitude estimations by determining station-specific scaling relations between the predominant period of the $P$ wave and event magnitude and by utilizing stations with optimal relations. Further, because individual stations are able to deliver an accurate early warning, the option of utilizing the technology in regions that lack a dense seismic network but are in need of seismic hazard mitigation becomes possible.
\end{abstract}

\section{Introduction}

Earthquake early warning systems hold the potential to reduce the damaging affects of earthquakes by giving a few seconds to a few tens of seconds warning before the arrival of damaging ground motion. Many early warning systems use a network of seismic instruments to determine earthquake magnitude and location (Anderson et al., 1995; Espinosa-Aranda et al., 1995; Wu et al., 1998; Wu and Teng, 2002; Allen and Kanamori, 2003; A. Lockman and R. M. Allen, unpublished manuscript, 2005), but here we focus on a single seismic station's ability to assess earthquake hazard using the first few seconds of the $P$ wave by calculating three parameters needed for early warning: event magnitude, hypocentral distance, and backazimuth. Rapidly estimating these parameters from the $P$ wave and using attenuation relations gives the timeliest estimate of the groundshaking hazard for early warning.

Operational early warning systems in Mexico City and Taiwan use a technique known as front detection to give early warning, an approach that involves calculating earthquake magnitude near the source and issuing a warning to populations a greater distance away. The Seismic Alert System in Mexico City uses the peak ground motion measured near the Guerro Gap subduction zone to estimate magnitude,

*Present address: Department of Earth and Planetary Science, University of California, Berkeley, 307 McCone Hall, Berkeley, California 947204767; rallen@berkeley.edu. and conveys this information to the population in Mexico City, $300 \mathrm{~km}$ away, providing $60 \mathrm{sec}$ or more warning of the impending ground motion (Anderson et al., 1995; Espinosa-Aranda et al., 1995). The Central Weather Bureau of Taiwan operates in a similar fashion, and can give a magnitude estimate about $22 \mathrm{sec}$ after the $P$ wave is detected and issue a warning to populations greater than $75 \mathrm{~km}$ from the epicenter (Wu et al., 1998; Wu and Teng, 2002).

A more advanced method of early warning uses the $\mathrm{P}$ wave to characterize event parameters, which gives an additional few seconds warning because it does not involve waiting for peak ground motion observations. Nakamura (1988) developed a system called UrEDAS, which uses the initial motions of the $P$ wave recorded at a single station to determine earthquake parameters. Allen and Kanamori (2003) and Lockman and Allen (unpublished manuscript, 2005) have also used a $P$-wave detection approach to determine earthquake magnitude, but in a manner that utilizes a network of seismic stations to increase the accuracy of magnitude estimates.

Here we assess the potential to accurately determine earthquake parameters using single seismic stations. We follow a similar approach to that used by Nakamura (1988) to estimate magnitude, hypocentral distance, and azimuth using $P$-wave records at single stations, and quantify the accuracy of these estimates at many stations across southern California. This analysis shows how single stations (or small clus- 
ters of stations) can provide early warning in regions without seismic networks, and how they can be used to maximize warning time at sites close to the epicenter. Results suggest that the accuracy of estimating event parameters for early warning largely depends on individual station behavior and site characteristics.

\section{Data Set}

We test the accuracy of an individual station's ability to determine earthquake source parameters by analyzing waveforms of 50 earthquakes in southern California that were recorded on three-component broadband velocity sensors within $150 \mathrm{~km}$ of the epicenter (Table 1, Fig. 1). The data set contains a catalog of events very similar to that of Allen and Kanamori (2003) and uses all events greater than magnitude 5.0 that occurred since 1995 plus the Northridge ( $M$ 6.7), Hector Mine (M 7.1), and Landers ( $M$ 7.3) earthquakes. Additionally, 38 events with magnitudes between 3.0 and 4.9 were randomly selected and included in the data set.

\section{Single-Station Characterization of Earthquake Parameters}

Earthquake early warning systems must rapidly measure event parameters a few seconds after the arrival of the $P$ wave. We begin by analyzing a single station's ability to determine the earthquake magnitude and follow with an analysis of a single station's capacity to determine the event location.

\section{Magnitude}

Previous work shows that earthquake magnitude can be estimated using a network of seismic instruments and the first few seconds of the $P$ wave through scaling relations between magnitude and the predominant period of the $P$ wave (Allen and Kanamori, 2003; Lockman and Allen, unpublished manuscript, 2005). These studies indicate that three different seismically active regions exhibit the same scaling between predominant period and earthquake magnitude, but there remains considerable variation in the predominant period measurements of individual stations. Certain stations show a well-defined scaling relation between predominant period and event magnitude, while others lack a scaling relation owing to scatter in the predominant period observations (Lockman and Allen, unpublished manuscript, 2005). Here we aim to determine which stations in the southern California TriNet network have optimal scaling relations for early warning applications and explore the potential causes of their increased magnitude-period sensitivity.

To assess the ability of a single station to rapidly determine magnitude, we selected stations that recorded more than five earthquakes with at least one with magnitude greater than 5.0 from the event data set. The predominant period was calculated from the vertical velocity component of the $\mathrm{P}$ wave after the waveform was passed through a 3$\mathrm{Hz}$ low-pass filter. We follow the approach of Allen and Kanamori (2003) and use the maximum predominant period $\left(T_{\max }^{p}\right)$ in the first $4 \mathrm{sec}$ of the signal, using a method described by Nakamura (1988):

$$
T_{i}^{p}=2 \pi \sqrt{\frac{X_{i}}{D_{i}}},
$$

where

$$
\begin{gathered}
X_{i}=\alpha X_{i-1}+x_{i}^{2} \\
D_{i}=\alpha D_{i-1}+\left(\frac{d x}{d t}\right)_{i}^{2} .
\end{gathered}
$$

$T_{i}^{p}$ is the predominant period for sample $i, x_{i}$ is the recorded ground velocity, $X_{i}$ is the smoothed ground velocity squared, $D_{i}$ is the smoothed velocity derivative squared, and $\alpha$ is a smoothing constant equal to 0.999 .

$T_{\max }^{p}$ was plotted as a function of earthquake magnitude for each station, and a best-fit line was determined by minimizing the absolute deviations. The average absolute magnitude error of each station was calculated using the deviation of each individual $T_{\max }^{p}$ observation from the best-fit line. Figure 2 shows the average magnitude errors for each station and the magnitude-period scaling relations for three stations. Station CWC (Fig. 2b) exhibits the least uncertainty in earthquake magnitude determination using $T_{\max }^{p}$. Other stations in the data set show a lesser ability to determine earthquake magnitude because of decreased sensitivity in the scaling relations, more scatter in the $T_{\max }^{p}$ observations, or both. Comparing the observed $T_{\max }^{p}$ for the same eight events at stations CWC and GSC demonstrates how $T_{\max }^{p}$ measurements, and ability to determine magnitude, vary among individual stations. While station CWC exhibits a clear magnitude-period scaling relation with little scatter, station GSC shows very different $T_{\max }^{p}$ observations for the same events and a poor scaling relation between $T_{\max }^{p}$ and magnitude (Fig. 2c). The $M 7.1$ Hector Mine earthquake was included in this analysis to provide a wide range of magnitudes, even though it is $262 \mathrm{~km}$ from station CWC and falls outside the usual maximum epicentral distance of $150 \mathrm{~km}$.

Figure $2 \mathrm{~d}$ shows the magnitude-period scaling relation for station SVD, one of the few stations that recorded all three large-magnitude events in the data set. Using the bestfit relation, this station could provide a moderately accurate magnitude estimate with an average error of 0.33 magnitude units. All event magnitude estimates using this station are within one magnitude unit, including the large-magnitude events.

\section{Earthquake Location}

In addition to providing magnitude estimates, another critical function of an early warning system is to determine 
Table 1

Event Source Parameters for Earthquakes in Southern California Used in This Study

\begin{tabular}{|c|c|c|c|c|c|c|}
\hline Date & Time & Magnitude & Latitude & Longitude & $\begin{array}{c}\text { Depth } \\
(\mathrm{km})\end{array}$ & $\begin{array}{l}\text { Number of Waveforms } \\
\text { Collected for Event }\end{array}$ \\
\hline 8/20/2001 & 7:34:23.1 & 3.0 & 34.044 & -117.250 & 15.7 & 26 \\
\hline $10 / 28 / 2001$ & $16: 29: 54.6$ & 3.0 & 33.929 & -118.296 & 23.6 & 13 \\
\hline $3 / 11 / 2000$ & 21:46:07.8 & 3.1 & 33.839 & -117.744 & 3.5 & 11 \\
\hline $9 / 17 / 2001$ & $1: 14: 49.0$ & 3.1 & 33.922 & -117.774 & 11.8 & 18 \\
\hline $3 / 17 / 2002$ & $5: 50: 43.1$ & 3.2 & 33.873 & -117.856 & 9.5 & 16 \\
\hline $9 / 16 / 2000$ & $13: 23: 41.3$ & 3.2 & 33.976 & -118.424 & 12.2 & 7 \\
\hline $2 / 18 / 2001$ & 6:09:32.1 & 3.3 & 33.675 & -116.809 & 16.7 & 20 \\
\hline $7 / 1 / 2002$ & 22:03:59.6 & 3.3 & 34.103 & -116.651 & 10.0 & 22 \\
\hline $3 / 25 / 2001$ & $0: 41: 25.2$ & 3.4 & 34.048 & -117.570 & 7.5 & 21 \\
\hline $4 / 20 / 2001$ & $9: 52: 12.2$ & 3.4 & 33.705 & -116.776 & 16.9 & 15 \\
\hline $2 / 13 / 2001$ & $3: 04: 35.6$ & 3.5 & 34.289 & -116.942 & 6.2 & 24 \\
\hline $1 / 30 / 2002$ & $18: 47: 57.3$ & 3.5 & 34.366 & -118.661 & 12.8 & 19 \\
\hline $4 / 13 / 2001$ & 11:50:12.4 & 3.6 & 33.878 & -117.688 & 3.6 & 15 \\
\hline $1 / 29 / 2002$ & 20:23:07.0 & 3.6 & 34.363 & -118.667 & 12.6 & 19 \\
\hline $7 / 30 / 2001$ & $23: 34: 17.9$ & 3.7 & 36.049 & -117.883 & 2.8 & 10 \\
\hline $5 / 14 / 2001$ & $17: 13: 30.2$ & 3.8 & 34.226 & -117.440 & 8.7 & 32 \\
\hline $1 / 29 / 2002$ & 6:08:01.8 & 3.8 & 34.365 & -118.664 & 14.4 & 25 \\
\hline $7 / 3 / 2001$ & $11: 40: 48.1$ & 3.9 & 34.264 & -116.764 & 3.3 & 27 \\
\hline $1 / 29 / 2002$ & $6: 00: 39.8$ & 3.9 & 34.370 & -118.668 & 14.2 & 26 \\
\hline $10 / 28 / 2001$ & $16: 27: 45.5$ & 4.0 & 33.922 & -118.270 & 21.1 & 35 \\
\hline $11 / 13 / 2001$ & $20: 43: 14.9$ & 4.1 & 33.317 & -115.700 & 5.5 & 9 \\
\hline $5 / 17 / 2001$ & $22: 56: 45.8$ & 4.1 & 35.796 & -118.046 & 8.4 & 17 \\
\hline 9/9/2001 & $23: 59: 18.0$ & 4.2 & 34.059 & -118.388 & 7.9 & 31 \\
\hline $1 / 29 / 2002$ & $5: 53: 28.9$ & 4.2 & 34.361 & -118.657 & 14.2 & 16 \\
\hline $1 / 14 / 2001$ & $2: 26: 14.0$ & 4.3 & 34.284 & -118.404 & 8.8 & 38 \\
\hline $2 / 21 / 2000$ & $13: 49: 43.1$ & 4.3 & 34.047 & -117.255 & 15.0 & 27 \\
\hline $7 / 20 / 2001$ & $12: 53: 07.5$ & 4.4 & 35.995 & -117.877 & 3.4 & 15 \\
\hline 4/5/2002 & 8:02:56.0 & 4.4 & 34.524 & -116.295 & 5.6 & 29 \\
\hline $10 / 16 / 1999$ & $22: 53: 41.2$ & 4.5 & 34.710 & -116.353 & 7.5 & 12 \\
\hline $10 / 16 / 1999$ & $20: 13: 37.6$ & 4.6 & 34.689 & -116.280 & 1.3 & 9 \\
\hline $6 / 26 / 2000$ & $15: 43: 07.5$ & 4.6 & 34.783 & -116.294 & 4.3 & 12 \\
\hline $10 / 16 / 1999$ & $11: 26: 04.7$ & 4.7 & 34.813 & -116.341 & 0.0 & 3 \\
\hline $7 / 17 / 2001$ & $12: 59: 59.1$ & 4.7 & 36.017 & -117.882 & 0.4 & 11 \\
\hline $10 / 16 / 1999$ & $10: 20: 52.6$ & 4.8 & 34.362 & -116.148 & 0.1 & 5 \\
\hline 7/17/2001 & $12: 07: 26.3$ & 4.8 & 36.014 & -117.861 & 7.0 & 11 \\
\hline $10 / 22 / 1999$ & 16:08:48.1 & 5.02 & 34.865 & -116.409 & 0.9 & 16 \\
\hline 3/7/1998 & $0: 36: 46.8$ & 5.04 & 36.076 & -117.618 & 1.7 & 5 \\
\hline $10 / 21 / 1999$ & $1: 54: 34.2$ & 5.06 & 34.874 & -116.391 & 1.0 & 5 \\
\hline $4 / 26 / 1997$ & $10: 37: 30.7$ & 5.08 & 34.369 & -118.670 & 16.5 & 10 \\
\hline 1/7/1996 & $14: 32: 53.0$ & 5.18 & 35.761 & -117.646 & 4.0 & 3 \\
\hline $3 / 6 / 1998$ & $5: 47: 40.3$ & 5.24 & 36.067 & -117.638 & 1.8 & 5 \\
\hline $3 / 18 / 1997$ & $15: 24: 47.7$ & 5.27 & 34.971 & -116.819 & 1.6 & 11 \\
\hline $11 / 27 / 1996$ & 20:17:24.1 & 5.31 & 36.075 & -117.650 & 1.2 & 3 \\
\hline 1/17/1994 & $23: 33: 30.7$ & 5.58 & 34.326 & -118.698 & 9.8 & 2 \\
\hline $10 / 16 / 1999$ & $12: 57: 21.0$ & 5.64 & 34.442 & -116.248 & 1.9 & 5 \\
\hline 9/20/1995 & $23: 27: 36: 27$ & 5.76 & 35.761 & -117.638 & 5.4 & 4 \\
\hline $10 / 16 / 1999$ & 9:59:35.2 & 5.77 & 34.678 & -116.292 & 10.8 & 7 \\
\hline $1 / 17 / 1994$ & $12: 30: 55.4$ & 6.7 & 34.213 & -118.537 & 18.4 & 5 \\
\hline $10 / 16 / 1999$ & 9:46:44.1 & 7.1 & 34.600 & -116.272 & 5.0 & 17 \\
\hline 6/28/1992 & $11: 57: 34.1$ & 7.3 & 34.200 & -116.440 & 1.1 & 2 \\
\hline
\end{tabular}

earthquake location. Knowledge of the hypocentral distance can be used to estimate the time until severe ground shaking begins at a location, as well as to provide estimates of the peak ground-shaking amplitudes when combined with a magnitude estimate. The backazimuth gives information about the direction of the propagating waves and can be used to determine which areas can expect severe ground shaking and should receive warning. Estimation of these two parameters is completely independent, and we therefore evaluate the error in each separately. It should also be noted that only the hypocentral distance is required for a single-station early warning system, as the amplitude of ground shaking can be estimated from event magnitude and epicentral distance alone. 


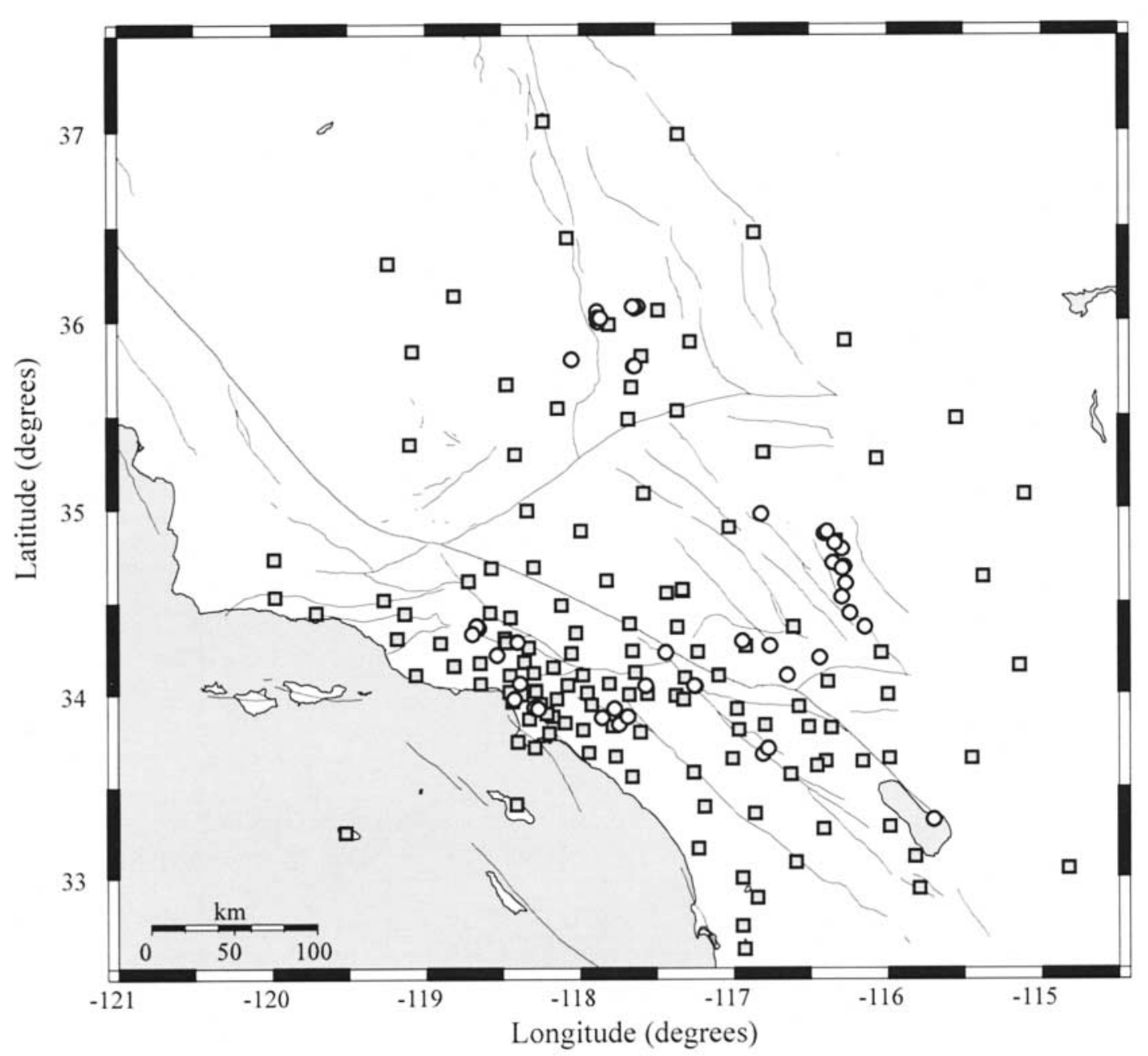

Figure 1. Map showing the locations of events (circles) and TriNet stations (squares) in southern California that provided three-component waveform data. Major faults are shown by thin gray lines.

We estimate hypocentral distance by developing a scaling relation between distance, $P$-wave amplitude, and $T_{\max }^{p}$. Attenuation relations describe how the amplitude of seismic waves decrease with distance and earthquake magnitude, and are commonly used to describe peak ground acceleration or velocity for large magnitude events (Campbell, 1981; Joyner and Boore, 1981; Abrahamson and Silva, 1997; Boore et al., 1997; Campbell, 1997; Fukushima and Irikura, 1997; Sadigh et al., 1997; Wald et al., 1999; Field, 2000). We determine our attenuation relations based on the $P$-wave amplitude and $T_{\max }^{p}$ in order to calculate hypocentral distance. We use the same functional form that Nakamura uses for UrEDAS (personal comm., 2004):

$$
\log R=\alpha \log \left(\frac{1}{T_{\max }^{p}}\right)+\beta \log \left(A_{p}\right)+\gamma
$$

where $R$ is the straight-line hypocentral distance, $A_{p}$ is the amplitude of the $P$ wave, and $\alpha, \beta$, and $\gamma$ are constants to be determined.
All earthquakes and waveforms in the data set were used to develop the regional attenuation relation shown in Figure 3. Constants $\alpha, \beta$, and $\gamma$ were determined using least-squares regression to be $-0.51118,-0.18298,1.59766$, respectively. Using this best-fit relation, $R$ is then determined for each event-station pair in the data set using the observed $A_{p}$ and $T_{\max }^{p}$ values. The errors in the hypocentral distance calculated using this approach are shown in Figure 4.

Figure $4 \mathrm{a}$ shows the hypocentral distance errors for each of the 28 stations that recorded more than five earthquakes and at least one with a magnitude greater than 5.0. Many stations consistently overestimate or underestimate the actual hypocentral distance, as indicated by clusters of data points on only one side of the zero-error line (for example, stations LKL and SHO). This consistent offset is most likely the result of site amplification effects. We take the simplest possible approach to correcting for these effects; we calculate a constant hypocentral distance correction factor for each station such that once applied the average error is zero. The corrections for each station are given in Table 2, and 

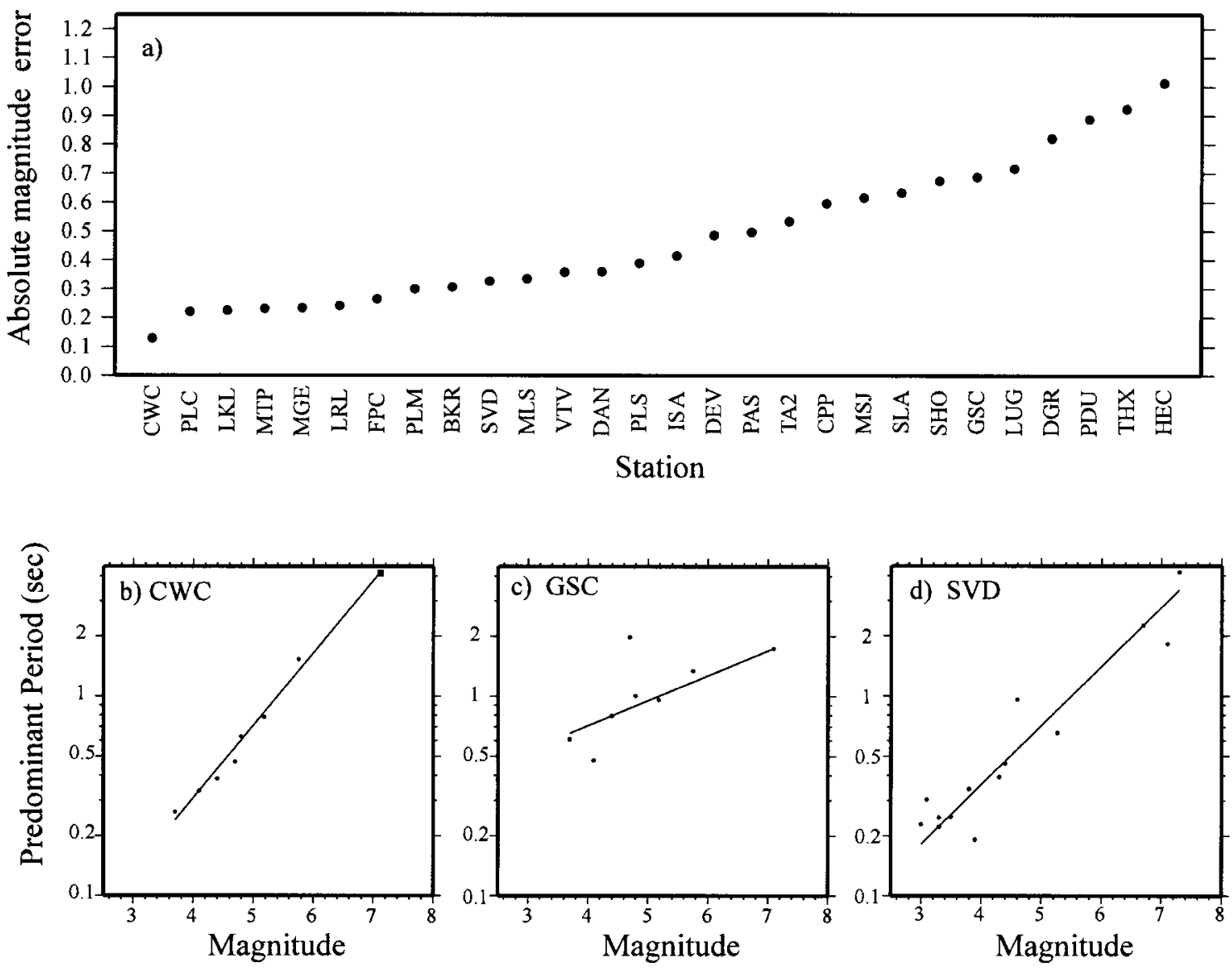

Figure 2. (a) The average absolute magnitude error for each station in the data set that recorded more than five earthquakes and at least one event with magnitude greater than 5.0. Stations are ordered according to their accuracy. Magnitude-period scaling relations are shown for stations (b) CWC, (c) GSC, and (d) SVD. Relations in (b) and (c) show variability in the predominant period observations of different stations for the same earthquakes. The $M 7.1$ Hector Mine earthquake was included in the analysis of station CWC (shown with a black square) even though it had an epicentral distance of $262 \mathrm{~km}$ and falls outside the maximum epicentral distance of $150 \mathrm{~km}$ used in the rest of the study. Station SVD (d) is shown as it is one of the few stations that recorded all three large-magnitude events; it shows typical errors in magnitude estimations for a single station.

the results of applying the correction factors are shown in Figure 5. The average absolute error in the hypocentral distance calculations for all stations and events is $23 \mathrm{~km}$ once the station corrections have been made, which is an improvement on the average error of $31 \mathrm{~km}$ without the site correction.

The backazimuth of an earthquake can be derived from $P$-wave particle motions based on the polarized nature of $P$ wave vibrations. $P$-wave particle motions lie in a vertical plane containing the station and earthquake epicenter. The horizontal station components indicate this plane, and the $180^{\circ}$ uncertainty can be resolved using motions of the vertical component.

Backazimuth calculations are determined using a method similar to Nakamura's (1988) as follows:

$$
\theta_{i}=180+\tan ^{-1}\left(\frac{R_{i}^{Z E}}{R_{i}^{Z N}}\right)
$$

where

$$
\begin{aligned}
& R_{i}^{Z E}=\alpha R_{i-1}^{Z E}+Z_{i} E_{i} \\
& R_{i}^{Z N}=\alpha R_{i-1}^{Z N}+Z_{i} N_{i}
\end{aligned}
$$

$\theta_{i}$ is the backazimuth estimate, $Z_{i}, N_{i}$, and $E_{i}$ are the vertical, north-south, and east-west components recorded at time $i$, and $\alpha$ is a smoothing constant. The backazimuth is calculated using the first $0.5 \mathrm{sec}$ of the $P$ wave. During this interval, $\theta_{i}$ is calculated continuously, and the final backazimuth is obtained by averaging the values of $\theta_{i}$. 


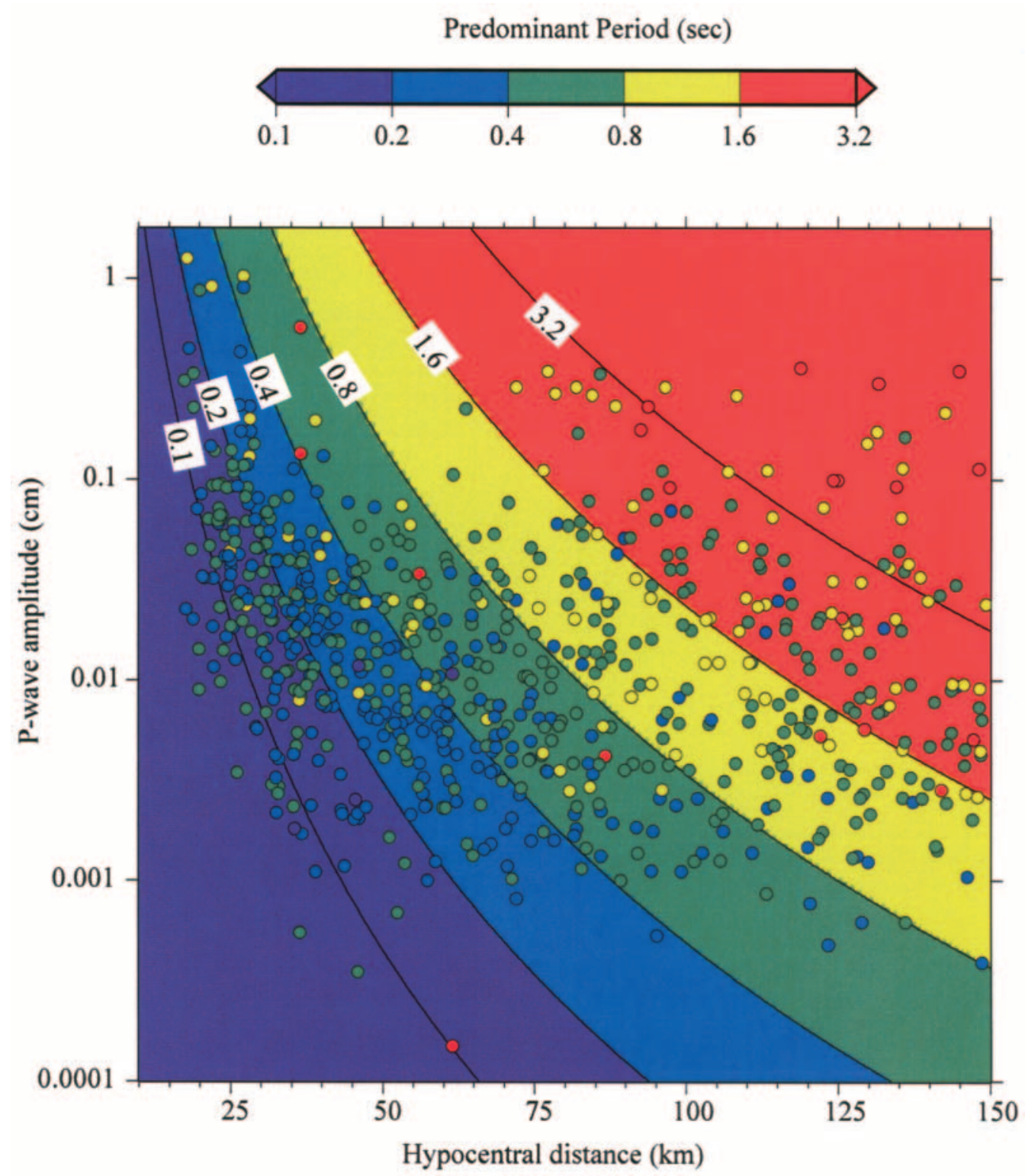

Figure 3. Plot showing the regional attenuation relation between hypocentral distance, $P$-wave amplitude, and the predominant period of the $P$ wave for all earthquakes in the data set. Circles show the observed values of individual stations, the background color scale shows the best-fit attenuation relations.

The average errors of the backazimuth calculations for each station that recorded more than five events and at least one event with magnitude greater than 5.0 are shown in Figure 6. There is considerable variation in the errors of the backazimuth calculations; some stations have average errors as low as $8.5^{\circ}$, and others have average errors as high as $100^{\circ}$.

\section{Discussion}

A correlation exists between stations that provide the best magnitude estimations and those that have the least error in the hypocentral distance calculations. This is not surprising as the methods used to calculate these parameters make use of the predominant period and depend on a sensitive magnitude-period scaling relation. We observe no correlation between stations that accurately estimate the backazimuth and the stations that accurately characterize the magnitude and hypocentral distance.

The ability to accurately determine event magnitude and hypocentral distance is limited by variations in $T_{\max }^{p}$ for a given magnitude earthquake and the variations in $T_{\max }^{p}$ observations made by different stations for the same events. Our data set does not contain enough earthquakes and we do not have sufficient information on the individual stations or the local geology to conclude which factors contribute to this variability, but a comparison of the $T_{\max }^{p}$ observations at 

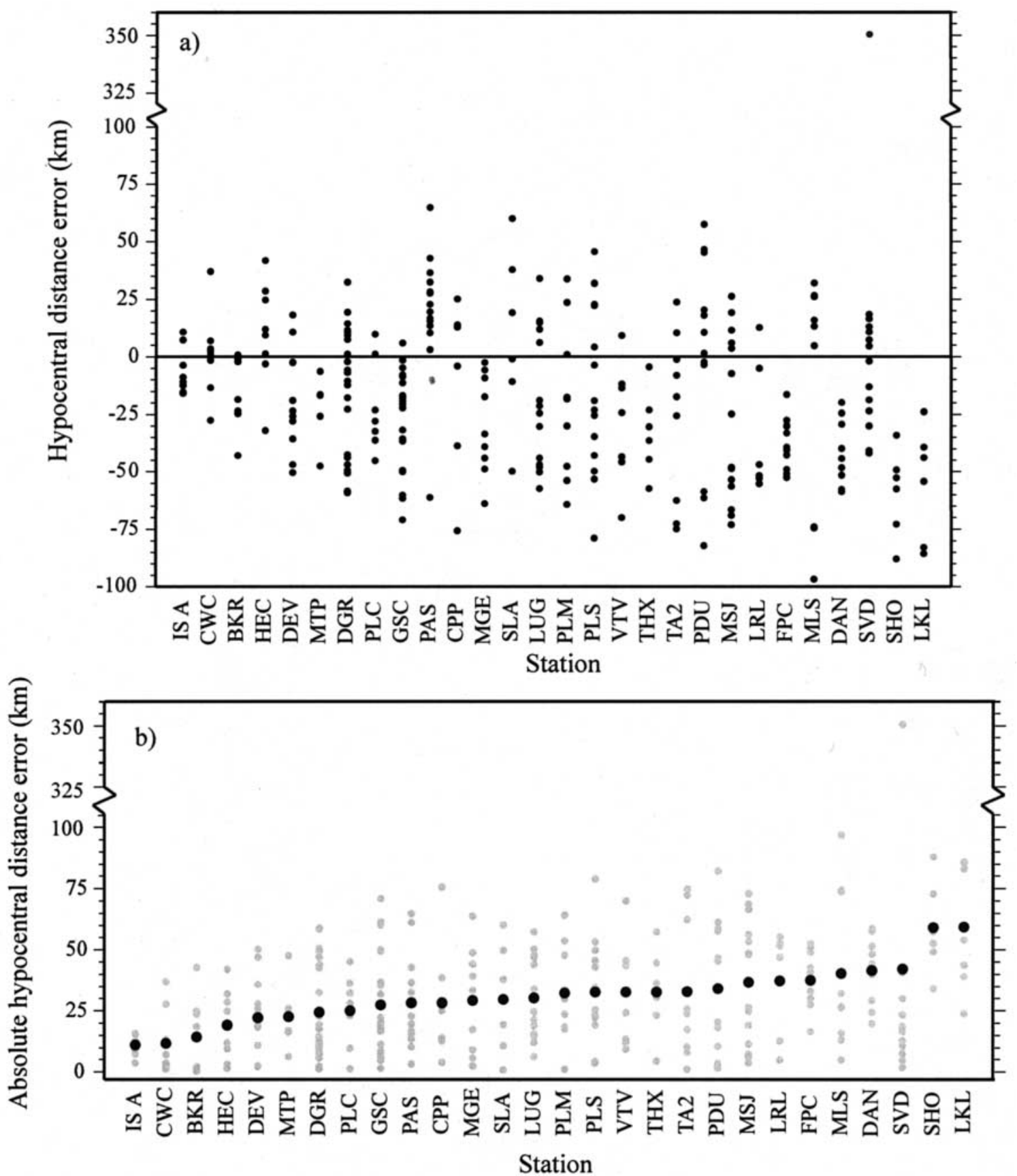

\section{Station}

Figure 4. (a) Hypocentral distance errors of earthquakes recorded by each station. Stations are ordered according to the average error. Hypocentral distances were estimated using the regional attenuation relation (without applying station-specific correction factors). Negative distance errors indicate the estimated hypocentral distance is short of the actual distance, and positive distance errors indicate the estimated distance is greater than the actual distance. (b) Absolute error in hypocentral distance calculations. Black dots show the average absolute error, and gray dots show the error of a single event.

stations CWC and GSC for the same events (Figs. 2b and c) provides insight into some of the possible causes of the observed variations.

Possible reasons that stations observe different $T_{\max }^{p}$ for the same earthquake include changes in epicentral distance, basin or structural effects causing interference, or local site effects. Epicentral distance is probably not a significant factor because magnitude-period scaling relations remain very similar at epicentral distances of 0-100 km (Allen and Kanamori, 2003), 0-150 km (Lockman and Allen, unpublished 
Table 2

Station Correction Factors Used to Account for Constant Offsets in the Hypocentral Distance Estimates

\begin{tabular}{lc}
\hline Station & $\begin{array}{c}\text { Hypocentral Distance } \\
\text { Correction }(\mathrm{km})\end{array}$ \\
\hline BKR & -14.26 \\
CPP & -11.06 \\
CWC & 0.9 \\
DAN & -41.63 \\
DEV & -17.34 \\
DGR & -14.79 \\
FPC & -37.94 \\
GSC & -27.91 \\
HEC & 10.14 \\
ISA & -7.41 \\
LKL & -59.4 \\
LRL & -33.36 \\
LUG & -18.59 \\
MGE & -29.3 \\
MLS & -14.05 \\
MSJ & -27.23 \\
MTP & -23.02 \\
PAS & 19.97 \\
PDU & -0.68 \\
PLC & -22.07 \\
PLM & -19.32 \\
PLS & -11.5 \\
SHO & -59.57 \\
SLA & 8.81 \\
SVD & 20.79 \\
TA2 & -25.36 \\
THX & -32.94 \\
VTV & -30.58 \\
\hline &
\end{tabular}

manuscript, 2005), and to greater distances, as demonstrated by the $T_{\max }^{p}$ observations at CWC, $262 \mathrm{~km}$ from the Hector Mine event. This is due to the limited effect of attenuation on frequency content for these short ray paths. Variable basin geometry and other structural features can diffract rays and create multiple interfering ray paths, which could alter the predominant period observations. Figure 7 shows stations CWC and GSC and the common event set for which $T_{\max }^{p}$ observations were made. The distribution of faults illustrates the structural complexity of the region, making it quite possible to have multiple interfering ray paths. It is noticeable that ray paths to CWC (which shows a good magnitudeperiod relation) are subparallel to dominant structural boundaries, while paths to GSC must cross such boundaries. The very local structure beneath individual stations may also affect the quality of $T_{\max }^{p}$ observations, as may local sources of noise. It is impossible for us to determine at this point what makes for a good station in terms of $T_{\max }^{p}$ observations, although it seems likely that local structure plays a major role.

\section{Implications for Early Warning}

Critical to the success of an early warning system is the ability to quickly and accurately determine earthquake magnitude and location. Utilizing the $P$ wave to estimate these parameters offers the most rapid method of early warning, but at the potential cost of increasing errors. We have shown that certain high-quality stations have the ability to estimate earthquake magnitude and hypocentral distance with a greater degree of accuracy than others. Although many early warning systems rely on a network of instruments to increase the accuracy of the warning, implementing and maintaining a dense seismic network for the purpose of early warning presents economic obstacles. However, developing a warning system that uses a single station or a small cluster of stations with well-defined magnitude-period relations and little scatter could provide earthquake source information with sufficient accuracy to provide warnings, but at a reduced cost. Although we have focused here on the use of single stations, a second, third, or fourth station could improve the robustness of the system. Requiring two singlestation warning systems to trigger before taking action would reduce the potential for false alarms. Earthquake source information from multiple stations operating as a cluster could also be combined to improve the accuracy of both the magnitude and the location estimates. The accuracy of magnitude estimates is improved by simple averaging between multiple stations. "Single-station" locations could be improved by using the average predominant period in equation (4), by minimizing the misfit between the location and hypocentral distance and azimuth estimates from each station, and by using trigger times to estimate the location, as is standard practice for seismic networks. Finally, our observations suggest that early warning systems that use dense networks could improve the accuracy of magnitude estimates by treating stations separately and using stationspecific scaling relations between the predominant period and event magnitude.

\section{Summary}

1. Single seismic stations are capable of providing useful estimates of earthquake source parameters using only the $P$ arrivals. Magnitude estimates within 0.3 magnitude units, hypocentral distance estimates with average absolute errors of $\pm 15 \mathrm{~km}$, and backazimuth estimates with average errors of $\pm 20^{\circ}$ are possible at the best $25 \%$ of TriNet stations in southern California. Other stations have larger errors, and their estimates are not as useful. Typically, the same stations provide good estimates of magnitude and hypocentral distance, as both are dependent on $T_{\max }^{p}$ observations that scale with magnitude. There is no correlation between stations that perform well in the backazimuth calculations and the magnitude and hypocentral distance estimations.

2. The ability of a single seismic station to characterize earthquake source parameters using $P$-wave arrivals opens the possibility of applying early warning technology in regions that need seismic hazard mitigation but lack a dense seismic network. A single station or a small 


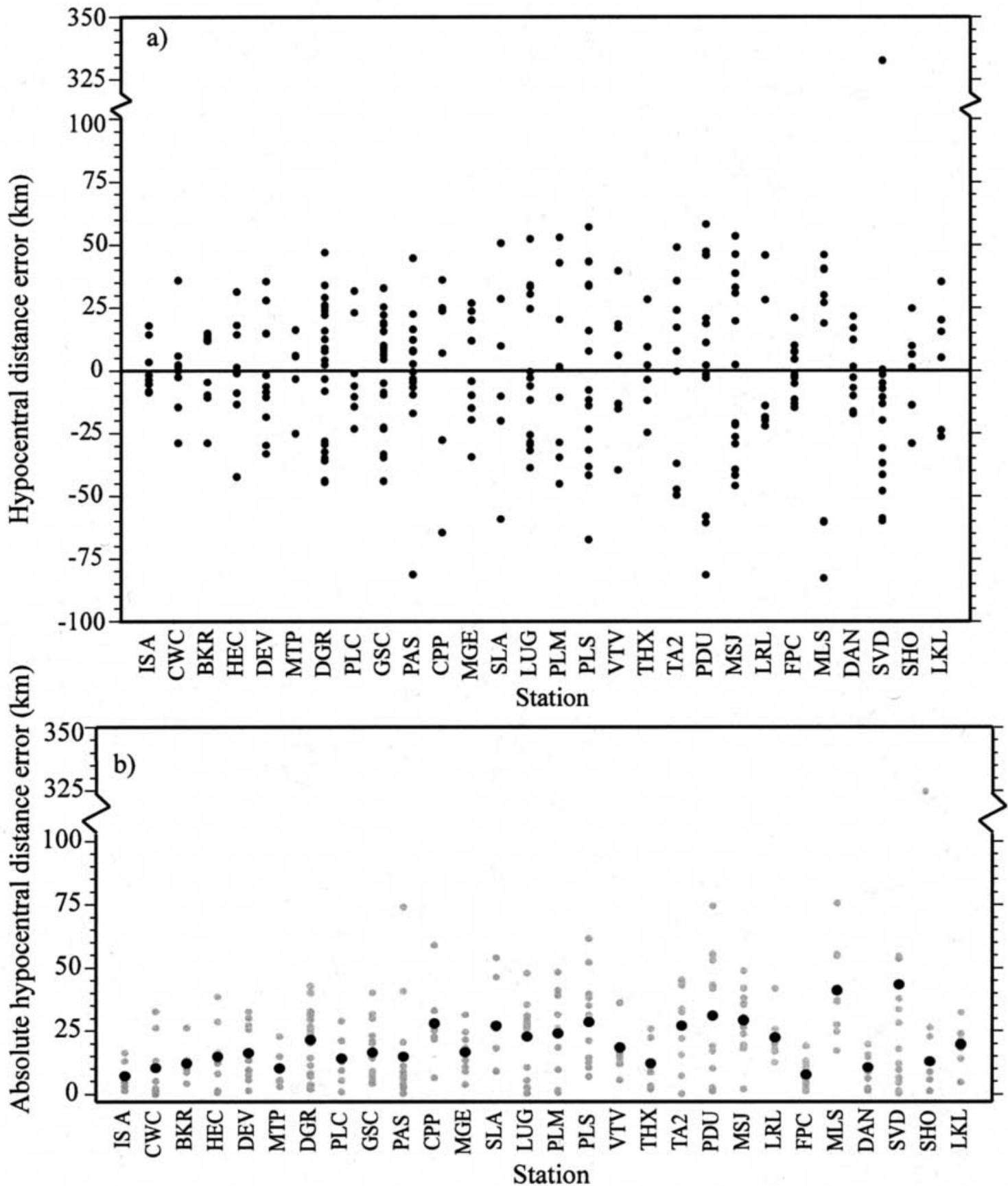

Figure 5. Plots showing errors in the hypocentral distance calculations using regional attenuation relations and station correction factors (Table 2). (a) Hypocentral distance errors of earthquakes recorded by each station. Negative distance errors indicate the estimated hypocentral distance is short of the actual distance, and positive distance errors indicate the estimated distance is greater than the actual distance. (b) Absolute error in hypocentral distance calculations. Black dots show the average error and gray dots show the error of a single event. The order of the stations is the same as in Figure 4. 


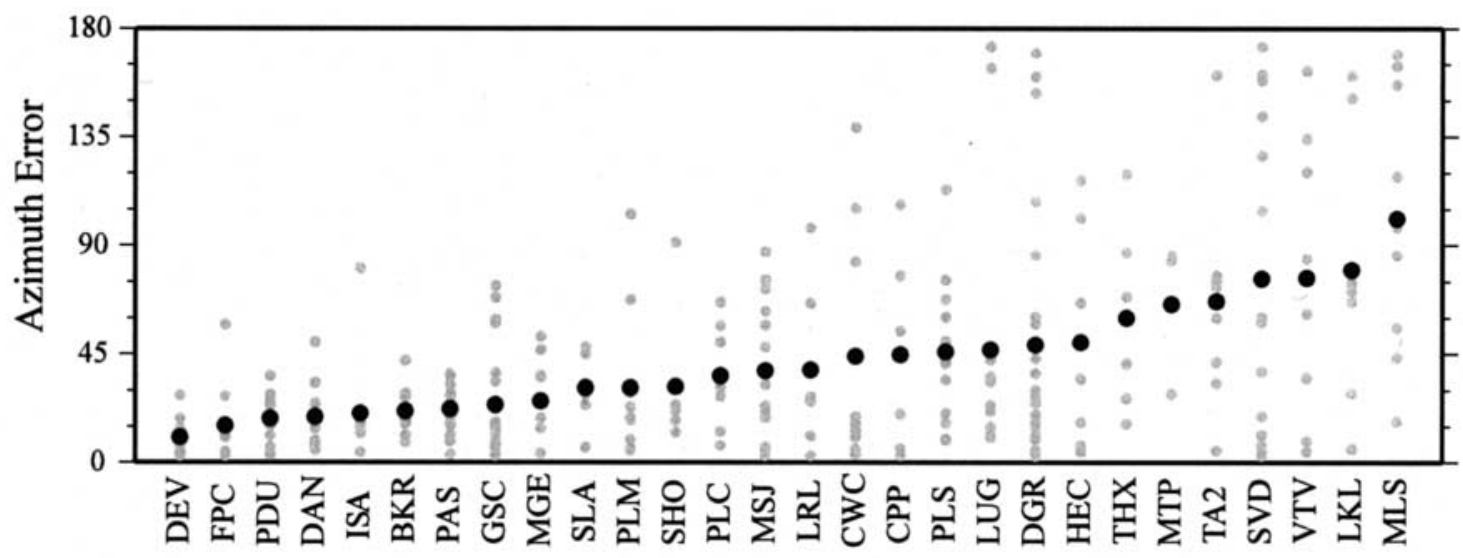

\section{Station}

Figure 6. Plot showing azimuth error calculations for stations in the data set, ordered by error. Black dots represent the average absolute error, and gray dots show the absolute error for a single event.

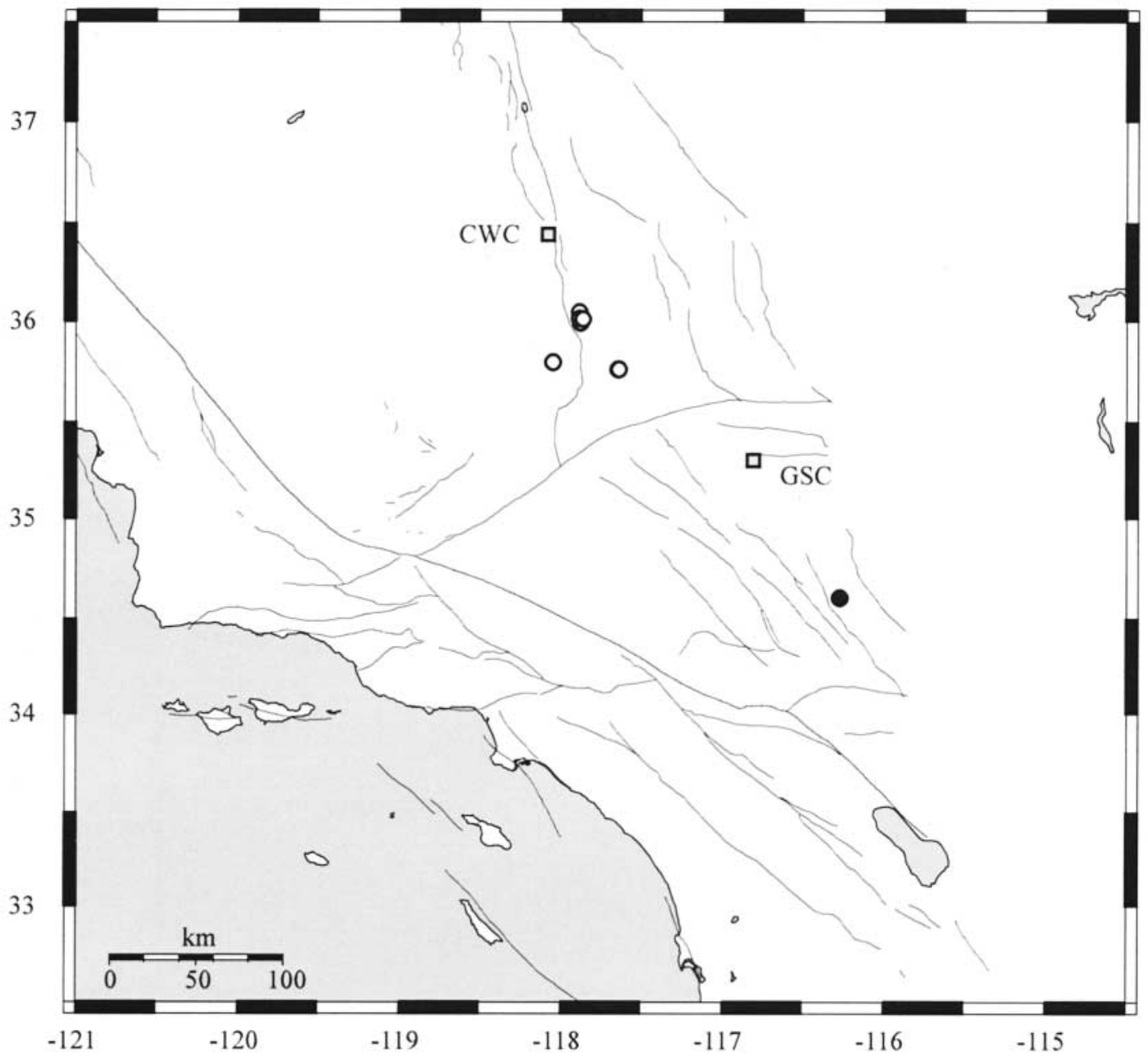

Figure 7. Map showing the locations of stations CWC and GSC and the eight events used to compare the predominant period observations made by both stations. The location of the magnitude 7.1 Hector Mine earthquake is shown by the solid black circle, and major faults are shown by thin gray lines. 
cluster of stations can bring these regions a low-cost mitigation tool and supplement other mitigation efforts.

3. Early warning systems that use $P$-wave front detection and a network of stations could provide more accurate estimates of earthquake source parameters if stationspecific scaling relations between $P$-wave characteristics and earthquake source parameters are developed. This requires a station to be operational for a period of time while the necessary observations are made. During this period, network-averaged scaling relations could be used.

\section{Acknowledgments}

We wish to thank Y. Nakamura for discussions regarding the UrEDAS system, two anonymous reviewers, and the editor, Andrew Michael, for helpful reviews and comments, which improved this manuscript. Data used in this study were obtained from the TriNet Network (now part of the California Integrated Seismic Network) (Hauksson et al., 2001). Funding for this study was provided by USGS/NEHRP awards 03HQGR0043 and 05HQGR0074, the Graduate School of the University of Wisconsin-Madison, and BP. The figures were produced with SAC and GMT (Wessel and Smith, 1995).

\section{References}

Abrahamson, N. A., and W. J. Silva (1997). Empirical response spectral attenuation relations for shallow crustal earthquake, Seism. Res. Lett. 68, 94-127.

Allen, R. M., and H. Kanamori (2003). The potential for earthquake early warning in southern California, Science 300, 786-789.

Anderson, J., R. Quaas, S. Krishna Singh, J. Manuel Espinosa, A. Jiminez, J. Lermo, J. Cuenca, F. Sanchez-Sesma, R. Meli, M. Ordaz, S. Alcocer, B. Lopez, L. Alcantara, E. Mena, and C. Javier (1995). The Copala, Guerrero, Mexico Earthquake of September 14, $1995\left(M_{\mathrm{w}}=\right.$ 7.4): a preliminary report, Seism. Res. Lett. 66, 11-39.

Boore, D. M., W. B. Joyner, and T. E. Fumal (1997). Equations for estimating horizontal response spectra and peak acceleration from western North American earthquakes: a summary of recent work, Seism. Res. Lett. 68, 128-153.

Campbell, K. W. (1981). Near-source attenuation of peak horizontal acceleration, Bull. Seism. Soc. Am. 71, 2039-2070.

Campbell, K. W. (1997). Empirical near-source attenuation relationships for horizontal and vertical components of peak ground acceleration, peak ground velocity, and pseudo-absolute acceleration response spectra, Seism. Res. Lett. 68, 154-179.

Espinosa-Aranda, J. A., A. Jimenez, G. Ibarrola, F. Alcantar, A. Aguilar, M. Inostroza, and S. Maldonado (1995). Mexico City seismic alert system, Seism. Res. Lett. 66, 42-53.

Field, E. H. (2000). A modified ground-motion attenuation relationship for southern California that accounts for detailed site classification and a basin-depth effect, Bull. Seism. Soc. Am. 90, S209-S221.

Fukushima, Y., and K. Irikura (1997). Attenuation characteristics of peak ground motions in the 1995 Hyogo-ken Nanbu earthquake, J. Phys. Earth 45, 135-146.

Hauksson, E., P. Small, K. Hafner, R. Busby, R. Clayton, J. Goltz, T. H. Heaton, K. Hutton, H. Kanamori, J. Polet, D. Given, L. M. Jones, and D. J. Wald (2001). Southern California Seismic Network: Caltech/ USGS Element of TriNet 1997-2001, Seism. Res. Lett. 72, 690-674.

Joyner, W. B., and D. M. Boore (1981). Peak horizontal acceleration and velocity from strong-motion records including records from the 1979 Imperial-Valley, California, earthquake, Bull. Seism. Soc. Am. 71, 2011-2038.

Nakamura, Y. (1988). On the Urgent Earthquake Detection and Alarm System (UrEDAS), Proc. 9th World Conference on Earthquake Engineering VII, Tokyo, Japan, 2-9 August 1988, 673-678.

Sadigh, K., C. Y. Chang, J. A. Egan, F. Makdisi, and R. R. Youngs (1997) Attenuation relationships for shallow crustal earthquakes based on California strong motion data, Seism. Res. Lett. 68, 180-189.

Wald, D. J., V. Quitoriano, T. H. Heaton, H. Kanamori, C. W. Scrivner, and C. B. Worden (1999). TriNet "ShakeMaps": rapid generation of peak ground motion and intensity maps for earthquakes in southern California, Earthquake Spectra 15, 537-555.

Wessel, P., and W. H. F. Smith (1995). New version of the Generic Mapping Tools released, EOS 76, 329.

Wu, Y. M., and T. L. Teng (2002). A virtual subnetwork approach to earthquake early warning, Bull. Seism. Soc. Am. 92, 2008-2018.

Wu, Y. M., T. C. Shin, and Y. B. Tsai (1998). Quick and reliable determination of magnitude for seismic early warning, Bull. Seism. Soc. Am. 88, 1254-1259.

Department of Geology and Geophysics

University of Wisconsin, Madison

1215 West Dayton Street

Madison, Wisconsin 53706

(A.B.L.) 